\title{
An Initial Study on the Coordination of Rod and Line Hauling Movements in Distance Fly Casting
}

\author{
${ }^{1}$ Ulrik Röijezon, ${ }^{2}$ Grunde Løvoll, ${ }^{3}$ Anders Henriksson, ${ }^{3}$ Michail Tonkonogi, ${ }^{1}$ Niklas Lehto
}

${ }^{1}$ Department of Health Sciences, Luleå University of Technology, Luleå, S-971 87, Sweden. ${ }^{2}$ Norwegian Institute for Water Research (NIVA), Section for Environmental Data Science Gaustadalléen 21, NO-0349 Oslo, Norway. ${ }^{3}$ Department of Sport and Health Sciences, School of Education, Health and Social Sciences, Dalarna University, S791 88, Falun, Sweden.

\begin{abstract}
Background. The double haul is a unique feature of single-handed fly casting and is used in both fly fishing and fly casting competition. The movement behaviour during the double haul has not been investigated in previous research. Objectives. Describe the coordination of the rod and line hauling movements during distance fly casting. Methods. Elite fly casters performed distance casting with four different fly rod and fly line set-ups used in fly fishing and fly casting competition. Rod and hauling movements were measured with a 3D motion analysis system. Results. The rod and line hauling movements were coordinated in an order whereby peak translational speed of the rod occurs prior to the peak speed of the angular rotation of the rod, and the peak speed of the angular rotation of the rod occurs prior to the peak speed of the line haul. This was consistent for all cast sequences, i.e., the back and forward false casts and the delivery cast, and for all four equipment set-ups, i.e., a shooting-head line cast with a relatively stiff fly rod and a long-belly line cast with three different fly rods with different stiffness and action curves. Results also showed differences in movement coordination between cast sequences and rod and line set-ups. Conclusion. Among elite casters, single-handed fly casting with double haul is coordinated in an order of events whereby the peak speed occurs first for the translation of the rod, then for the rotation of the rod and finally for the line haul.
\end{abstract}

KEY WORDS: Fly Fishing, Long-Belly Line, Movement Behavior, Shooting-Head Line.

\section{INTRODUCTION}

Sport, or recreational, fishing is a highly popular outdoor activity practiced on all continents (1). Fly fishing is a specific form of recreational fishing where a relatively heavy line is used to cast a very light artificial fly commonly imitating an insect or small fish. One of the challenges, but also charms, with fly fishing is the complexity and skills involved in the casting movements. To become a skilled fly fisher requires at a minimum some basic skills in fly casting, and it is common that fly fishers practice specific fly casting techniques both on water and on land between fishing trips. Fly casting is also practiced as an official sport worldwide. Distance and accuracy casting with a single-handed fly rod is practiced in two different disciplines within the International Casting Sport Federation (ICSF), i.e., Tournament Casting and Competition Fly

*. Corresponding Author:

Ulrik Röijezon

E-mail: ulrik.roijezon@1tu.se 
Casting. Tournament Casting involves relatively heavy fast sinking lines and specialized rods; Competition Fly Casting is, on the other hand, performed with gear and floating lines that are also normally used for fishing. This study focuses on fly casting techniques when casting with equipment used in Competition Fly Casting, and thereby also during fly fishing.

Maximum distance casting with a singlehanded fly rod is performed in two different events in Competition Fly Casting; these are Trout Distance and Sea Trout Distance. In the event Trout Distance, a long fly line with a long taper is used, a so-called long-belly line (2), and in fishing situations this type of line is commonly used when fishing for freshwater species like trout, grayling and arctic char with small to medium-sized flies. In the Sea Trout Distance event, a heavy but shorter line is used, a so-called shooting-head, and this type of line is commonly used when fishing for sea trout, salmon and pike and saltwater fishing, with big and/or heavy flies. The main difference between casting the two types of line for distance is the length of airborne line (often called line carry) prior to the final delivery cast. With a long-belly line, significantly more line is kept in the air than with a shootinghead, which has a limited length and where distance is gained through "line shoot" by letting go of the line at the end of the final delivery cast.

In both the Trout Distance and Sea Trout Distance events, the overhead cast technique is used, meaning that the line is held in motion above ground during the complete cast, creating loops that unroll toward the end of each cast sequence. The overhead cast can be divided into the back cast and the forward cast, which are commonly performed in several sequences, so-called false casts (Fig. 1), before the launch of the final forward cast. The final forward cast is here referred to as the delivery cast, i.e., the caster lets go of the line, which is propelled forward toward a specific target, e.g., a rising fish, or as far as possible as in Competition Fly Casting. The overhead cast is commonly performed together with the so-called double haul, which involves pulling the line, with the hand not holding the fly rod, during the back, forward and delivery casts (Fig. 1). A major purpose of the double haul is to increase line speed and thereby the kinetic energy of the line to increase casting distance. The coordination of the movements of the rod and the line haul is therefore important for maximizing the line speed and thus for the casting distance. The fact that the fly rod is not stiff and bends and unbends in response to input from the caster will also impact the coordination of movements for optimal distance. Theoretically, optimal coordination would be to achieve maximum line haul speed simultaneously with the time point of maximum speed of the rod tip, which occurs at the end of the unbending of the rod (3).

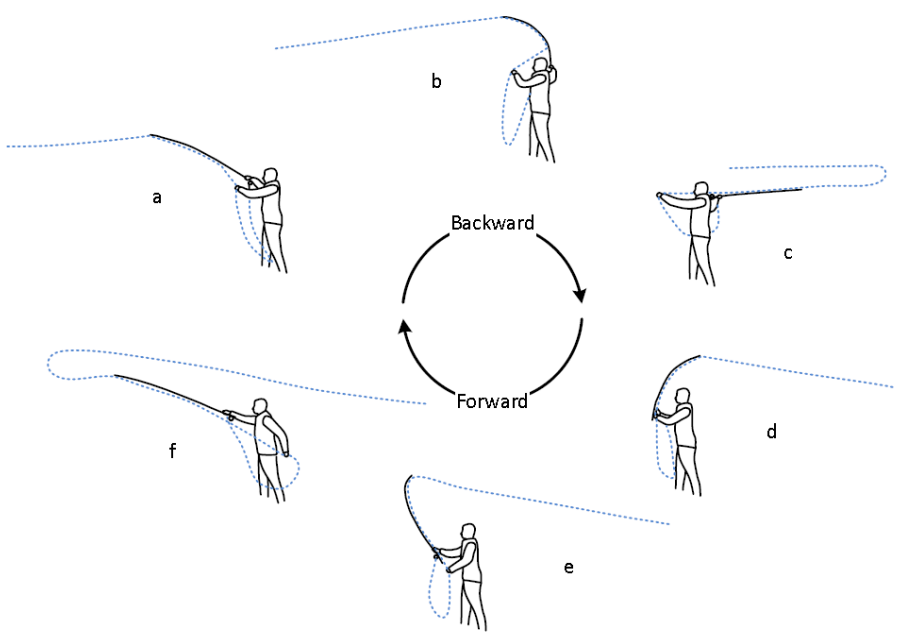

Figure 1. Illustration of the double haul during the back cast (above) and forward cast (below). The diagram illustrates approximately: a) initiation, b) mid phase and c) final position of double haul in back cast, and d) initiation, e) mid phase and f) final position of double haul in forward cast. 
The coordination of the arm movement has been investigated in several different overhead casting and racquet sports, including baseball (46), American football $(7)$, javelin $(8,9)$, team handball, volleyball and tennis $(10,11)$. Common to these sports is that the trunk and arm movement is performed principally in proximal to distal segmental sequencing, i.e., the initiation of movement or maximum rotational speed occurring first at the trunk, thereafter the shoulder, the elbow and finally the wrist $(6,8$ 10). Some variations to this proximal to distal sequencing have been reported, especially regarding the speed of the internal rotation of the shoulder, which in some situations peaks after elbow extension $(4,6,8,10,12)$. One previous study has investigated the coordination of arm movement during fly casting (13). This study included experienced fly fishers and instructors performing short to long casts without double haul, and the results revealed a similar proximal to distal coordination of the casting arm as mentioned above, i.e., peak speed of shoulder internal rotation was followed by elbow extension and finally ulnar deviation of the wrist (13). The double haul, which involves a twohanded coordination movement during the backward, forward and delivery casts, is a unique feature of singlehanded fly casting, and is highly useful for reaching long distances in fishing and is used by all competitors in fly casting. No study has however, to our knowledge, investigated the coordination of the movements of the rod and the line haul in maximum distance casting with single-handed fly rod.

As mentioned above, different lines are used in distance casting, including long-belly and shooting-head lines. Moreover, different fly rods have different physical characteristics, e.g., different stiffness and different bending (action) curves, with some fly rods bending relatively more at the tip section while others bend relatively less at the tip section but instead relatively deeper down the blank (14). Most competitors in fly casting prefer rather stiff rods with tip to medium action, which are commonly referred to as fast fly rods. These rods have relatively high frequency and react relatively swiftly during the unbending (straightening) of the rod. There are several benefits of having a flexible (bending) rod $(3,15,16)$. First it allows for a relative straight tip path during significant parts of the casting sequence. Secondly it acts as an elastic spring, storing elastic energy during the bending phase and releasing this energy during unbending. This makes the rod act like a gear-shift (with delay), where speed is put on top of the caster's direct speed input (rotation and translation). Third the elastic materials used in fly rods (the most common material being carbon fibre) are both light and strong, thus allowing for long light rods with low swing weight and lots of leverage.

It seems likely that different lines and different fly rod characteristics have different influences on the coordination of arm movements during the cast in order to optimize casting performance. Due to the bending, or loading, of the fly rod during back, forward and delivery casts, it seems theoretically reasonable that the maximum speed of the line haul would occur shortly after the maximum speed of the angular rod rotation because of the slight delay of rod tip movement related to the flexibility and inertia of the fly rod during casting. It also seems reasonable that the movement coordination between rod hand and line hand would be related to the type of line, i.e., long-belly or shootinghead, due to the difference in line length and thereby also difference in the time it takes for the line loop to straighten in the back and forward cast, and also related to the physics of the fly rod, i.e., stiff and fast rods compared to relatively soft and slow fly rods, due to the difference in time it takes for the rod to straighten.

Knowledge about the coordination of arm movements of the rod hand and the line hand is important for instructions, practice and analyses of casting technique among fly fishers and competitors in fly casting. In this study we investigated the movement coordination of the rod butt (the part of the rod below the reel seat of the fly rod) and the line hand (the hand holding and hauling the fly line). Casting was performed by elite casters competing in Competition Fly Casting. The equipment used was regular offthe-shelf fly fishing gear, which is the same or similar to what is used in the competition events 
Trout Distance and Sea Trout distance as well as in actual fishing situations. For the Trout Distance event, we also investigated rod and line haul coordination when using different fly rods with different stiffness and bending actions but the same line. We hypothesized that: 1) the maximum speed of the line haul would occur slightly after the maximum speed of the rotation of the rod butt, both in the back, forward and delivery casts; 2) that the peak speed and time difference of peak speed between rod and line hand would differ between casting a short line (shooting-head) compared to a long line (longbelly); and 3) that the delay of the peak speed of the line haul would be greater in a softer rod compared to a stiffer rod using the same line.

\section{MATERIALS AND METHODS}

The study was performed indoors in the sports hall at Dalarna University, Campus Falun. An experimental design was used that evaluated the coordination of the rod and line hand movements during the various cast sequences of overhead single-handed fly casting with double haul using four different equipment set-ups. All participants, as members of the national elite team in Competition Fly Casting, contributed to the design of the study and gave oral consent to participate.

Participants. Four male casters aged from 27 to 42 years - all experienced fly fishers and competitors in Fly Casting - participated in the study, see Table 1 for participant characteristics. This group of participants constituted almost half of the casters in the Swedish elite group at the time of data collection. Each caster performed 15 casts with four different fly casting equipment set-ups, i.e., each caster performed 60 casts altogether. The task was to cast as far as possible using the overhead cast with double haul. The fly lines, rods, reels and leaders were the same as those commonly used for fly fishing and Competition Fly Casting in the events Trout Distance and Sea Trout Distance.

Equipment. For the Trout Distance event, each caster cast a long-belly line (Mastery Expert Distance \#5, Scientific Anglers, USA) with three different fly rods, all 9 feet long (2.74 meters) but with different stiffness and action curves: Trout 1) the participant's own competition fly rod (see below), Trout 2) a Sage
TCX \#5, which was considered the benchmark for a stiff fly rod with tip action, and Trout 3) a Kingfisher Diamondback \#4-5, which was considered a very soft rod with deep action curve. In Trout1, casters 1 and 4 used MSX Black Diamond 690-4, caster 2 used MSX Emerald 790-4 and caster 3 used Zpey Competition 590-4, all considered to be stiff rods.

Table 1. Participant characteristics (Mean \pm SE or Sum and percentages).

\begin{tabular}{lc}
\hline Participants [male] & $4(100 \%)$ \\
Age (years) & $36( \pm 7)$ \\
Height $(\mathrm{cm})$ & $182( \pm 6)$ \\
Weight $(\mathrm{kg})$ & $89( \pm 14)$ \\
Handedness [right] & $4(100 \%)$ \\
Experience of fly fishing (years) & $22( \pm 9)$ \\
Experience of Competition Fly Casting (years) & $3( \pm 1)$ \\
\hline
\end{tabular}

Handedness is defined as the hand holding the fly rod.

For the Sea Trout Distance event, each caster cast his own shooting-head line, length varying between 15 to 16.5 meters. Each caster also used his own fly rod with a maximum length of 10 feet (3.05 meters), rod lengths varying between 9.5 and 10 feet among casters. Casters 1 and 3 used a MSX Sapphire 810-4 (3.05 meter) rod with a Barrio GT 140 \#8 cut to a 16.5 meter and 27 gram shooting-head, and casters 2 and 4 used MSX Black Diamond 895-4 (2.90 meters) rod with a Custom Loop shooting-head cut to 15 meters and 27 grams.

For all tackle set-ups, a tapered leader of 2.7 meters was used and a piece of yarn was tied at the end of the leader as a "fly".

A 50-meter-long tape measure was placed on the floor of the casting field to measure casting distance.

The three-dimensional (3D) motion of the fly rod butt and the left hand (the hand hauling the fly line) was measured with Xsens ${ }^{\circledR}$ motion capture system (Xsens Technologies B.V., Netherlands). Motion sensors, inertial measurement units or IMUs, were fixed to the upper and lower limbs, the head and trunk, and the butt of the fly rod. The sensors work well for placement on the body and the butt of the rod, but due to their size and weight it was not possible to attach a sensor to the rod tip. Altogether 23 sensors were used during the measurements. On-line data were transmitted 
wirelessly to a laptop during the assessments. The accuracy of assessments with Xsens ${ }^{\circledR}$ motion capture system has been shown acceptable for human motion analysis, including upper limb movements $(17,18)$.

Procedure. Anthropometric measures were assessed for each caster, and the Xsens ${ }^{\circledR}$ system was calibrated according to the manufacturer's instructions. One to two warm-up casts were performed prior to the measurements. Fifteen casts were performed with each of the four rod and line set-ups starting with Trout 1 , followed by Trout 2, Trout 3 and Sea Trout by each caster. The kinematics of casting performance and casting distance was recorded for the separate casts.
Outcome measures. Outcome variables used for analyses were maximum translational and rotational speed of the rod butt $\left(v_{\text {rod }}\right.$ and $\theta_{\text {rod }}$, respectively) and maximum speed of the movement of the line hand relative to the rod butt $\left(\mathrm{v}_{\text {line }}\right)$. To investigate the sequential coordination of rod and hand movements, we calculated the time interval between the time points of maximum (peak) speed of the translational and the rotational motion of the rod butt $\left(\Delta \mathrm{t}_{1}\right)$ and the motion of the line hand relative to the rod butt rotation $\left(\Delta \mathrm{t}_{2}\right)$ and the line hand relative rod translation $\left(\Delta \mathrm{t}_{3}\right)$ : note that by definition these time differences are related through $\Delta \mathrm{t}_{3}=\Delta \mathrm{t}_{1}+\Delta \mathrm{t}_{2}$. The time intervals are also indicated in Figure 2.

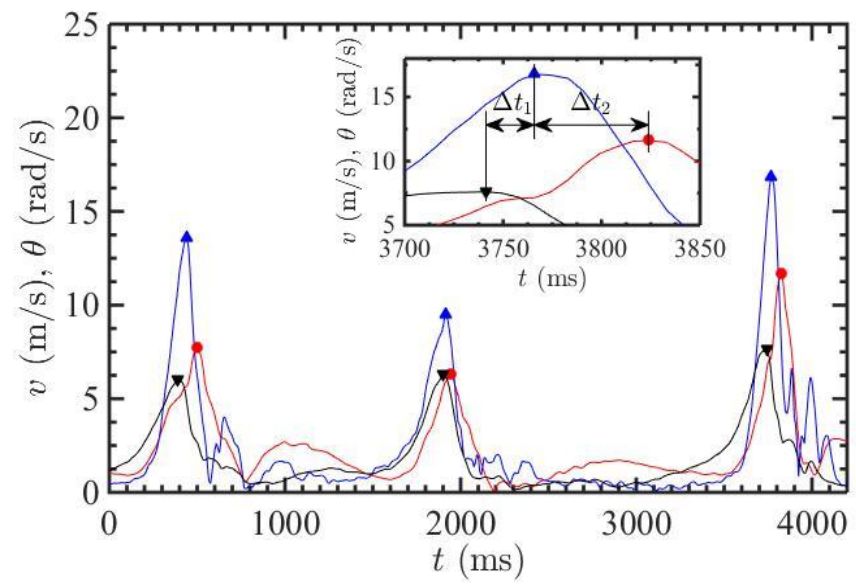

Figure 2. Speed profile of the rod and hand movements. The translational speed $(\mathrm{m} / \mathrm{s})($ black line) and angular rotational speed $(\mathrm{r} / \mathrm{s})$ (blue line) of the rod and the speed of the line hand relative to the rod butt $(\mathrm{m} / \mathrm{s})($ red line), presenting from left to right the final forward false cast, the final back false cast and the delivery cast. The figure illustrates the sequential coordination of rod and double haul movements where $\Delta t_{1}$ represents the time interval between peak speed of rod translation and rod rotation and where $\Delta t_{2}$ represents the time interval between the peak speed of rod rotation and the peak speed of line hand relative to rod butt. $\Delta \mathrm{t}_{3}$ is the sum of $\Delta \mathrm{t}_{1}$ and $\Delta \mathrm{t}_{2}$. Time ( $\mathrm{t}$ ) is presented in milliseconds (ms).

Data processing was performed using a commercial software package (MATLAB ® Release 2012b, The MathWorks, Inc., Natick, MA). A MATLAB program was developed to visualize the motion data and to calculate the outcome variables, $v_{\text {rod }}, \theta_{\text {rod }}$ and $v_{\text {line. }}$. Detection of the maximum translational and rotational speed was made by the built-in peak detection algorithm. In order to filter out the back and forward false cast and delivery cast, peaks in the product $v_{\text {rod }} \mathrm{x} \theta_{\text {rod }} \times v_{\text {line. }}$ were detected using a threshold that was individually adapted for each data set. After the casts had been detected, the individual outcome variables, $v_{\text {rod }}, \theta_{\text {rod }}$ and $v_{\text {line. }}$, were calculated and stored using the same peak detection algorithm. A visual examination of the 
plotted data was used to confirm that all the peaks were detected correctly.

Statistical Analysis. Statistical analyses were performed in SPSS ${ }^{\circledR}$ version 22. For descriptive and statistical analyses, the final back and forward false cast and delivery cast sequences were used for all casts performed with each of the four tackle set-ups, i.e., Trout 1, Trout 2 and Trout 3 and Sea Trout. Univariate analyses of variance (ANOVAs) were used for statistical analyses of differences in peak speed time differences in rod and line hand (i.e., $\Delta \mathrm{t}_{1}, \Delta \mathrm{t}_{2}$ and $\left.\Delta \mathrm{t}_{3}\right)$ as well as differences in rod and line hand peak speed (i.e., $v_{\text {rod }}, \theta_{\text {rod }}$ and $v_{\text {line }}$ ) between back and forward false cast and delivery cast sequences with pooled data from all equipment set-ups. Univariate ANOVAs were also used for statistical analyses to investigate any differences of the coordination variables of time differences (i.e., $\Delta \mathrm{t}_{1}, \Delta \mathrm{t}_{2}$ and $\Delta \mathrm{t}_{3}$ ) and peak speed variables (i.e., $v_{\text {rod }}, \theta_{\text {rod }}$ and $v_{\text {line }}$ ) between the four equipment set-ups (Trout 1, Trout 2 and Trout 3 and Sea Trout) during the separate cast sequences, i.e., back and forward false cast and delivery cast. Post hoc analyses were performed with Bonferroni adjustments

\section{RESULTS}

On average the longest casts were performed with Sea Trout equipment, and among the three different Trout equipment setups, the longest casts were performed with Trout 1, i.e., the respective casters preferred competition rod. Descriptive data of the longest casts with the different equipment by the separate casters, including mean distances and SE for the whole group, are presented in Table 2.
Table 2. The longest casts (in meters) with the four different equipment set-ups performed by the four casters.

\begin{tabular}{ccccc}
\hline Caster & Sea Trout & Trout 1 & Trout 2 & Trout 3 \\
\hline 1 & 38.2 & 36.8 & 34.0 & 30.8 \\
2 & 34.4 & 28.4 & 30.0 & 29.5 \\
3 & 31.2 & 33.3 & 30.0 & 29.6 \\
4 & 37.2 & 34.6 & 31.8 & 32.7 \\
Mean & 35.3 & 33.3 & 31.5 & 30.7 \\
SE & 3.1 & 3.6 & 1.9 & 1.5 \\
\hline
\end{tabular}

Results are presented for the final back and forward false cast sequences and the delivery cast sequence for each cast. Some casts were excluded due to mishaps during casting, e.g., line tangling or technology fails. Altogether 638 cast sequences were analysed, of which 212 were back casts, 212 were forward false casts and 214 were delivery casts.

The sequential coordination of the rod and line haul movements is illustrated in Figure 2, presenting a representative profile of the speed of the rod translation and rotation, and the speed of the line hand relative to the rod, for one cast by one of the fly casters. The descriptive analysis of the sequential coordination of the movement of the fly rod and line haul shows that in general the peak translational speed of the rod occurred prior to the peak speed of the angular rotation of the rod; moreover, the peak speed of the angular rotation of the rod occurred before the peak speed of the line haul. This was consistent for all equipment set-ups (i.e., Sea Trout \& Trout 1-3) and for the back and forward false casts and the delivery cast sequences illustrated by the positive measures of the coordination variables $\Delta \mathrm{t}_{1}, \quad \Delta \mathrm{t}_{2}$ and $\Delta \mathrm{t}_{3}$, respectively, as displayed in Figure 3, and for the delivery cast also in Table 3.

Table 3. Sequential coordination and peak speed of rod and line hand during the delivery casts (Mean \pm SE).

\begin{tabular}{lccccrl}
\hline Variable & Sea Trout & Trout1 & Trout2 & Trout3 & \multicolumn{1}{c}{ F } & \multicolumn{1}{l}{ Sig } \\
\hline$\Delta \mathrm{t}_{1}(\mathrm{~ms})$ & $50.0(27.6)^{*}$ & $34.7(15.7)$ & $28.3(22.7)$ & $31.6(19.3)$ & 10.7 & $<0.001$ \\
$\Delta \mathrm{t}_{2}(\mathrm{~ms})$ & $47.6(24.4)^{*}$ & $62.9(20.4)$ & $60.2(17.5)$ & $62.4(22.1)$ & 6.5 & $<0.001$ \\
$\Delta \mathrm{t}_{3}(\mathrm{~ms})$ & $97.5(18.3)$ & $97.6(19.8)$ & $88.6(17.3)$ & $94.0(17.8)$ & 3.1 & 0.028 \\
$v_{\text {rod }}(\mathrm{m} / \mathrm{s})$ & $6.8(0.9)^{*}$ & $7.3(1.0)$ & $7.4(0.9)$ & $7.5(0.9)$ & 5.9 & 0.001 \\
$\theta_{\text {rod }}(\mathrm{rad} / \mathrm{s})$ & $14.5(2.0)^{*}$ & $15.5(1.2)$ & $15.7(1.0)$ & $17.0(1.4)^{*}$ & 22.6 & $<0.001$ \\
$v_{\text {line }}(\mathrm{m} / \mathrm{s})$ & $9.9(1.4)$ & $9.7(1,5)$ & $10.0(1.4)$ & $10.3(1.2)$ & 1.6 & 0.190
\end{tabular}

Sequential coordination presented as the time interval between the time points of the peak speed of: the translational and the rotational motion of the rod butt $\left(\Delta \mathrm{t}_{1}\right)$, the motion of the line hand relative to the rod butt rotation $\left(\Delta \mathrm{t}_{2}\right)$ and the line hand relative to rod butt translation $\left(\Delta \mathrm{t}_{3}\right)$. $v_{\text {rod }}$ : peak speed rod translation. $\theta_{\text {rod }}$ : peak speed rod rotation. $v_{\text {line }}$ : peak speed line hand. * Post-hoc test (Bonferroni) revealed a significant difference $(\mathrm{p} \leq 0.01)$ between Sea Trout and Trout $1-3$.

*' Post-hoc test (Bonferroni) revealed a significant difference $(\mathrm{p}<0.01)$ between Trout3 and Trout1-2 \& Sea Trout. 
Analysis of variance with pooled data from the different equipment set-ups showed a significant difference in the time differences of peak speed between rod translation and rod rotation $\left(\Delta \mathrm{t}_{1}\right) \quad(F=81.6, \quad p<0.01)$, peak $\operatorname{rod}$ rotational speed and line haul speed $\left(\Delta \mathrm{t}_{2}\right)$ $(F=523, p<0.01)$ and peak rod translation speed and peak line haul speed $\left(\Delta \mathrm{t}_{3}\right)(F=943, p<0.01)$ between the different cast sequences. Post hoc analyses showed that the time differences were consistently smallest during the back cast and largest during the forward false cast $(p<0.01$ for all comparisons), see Figure 3 for descriptive presentation of data.

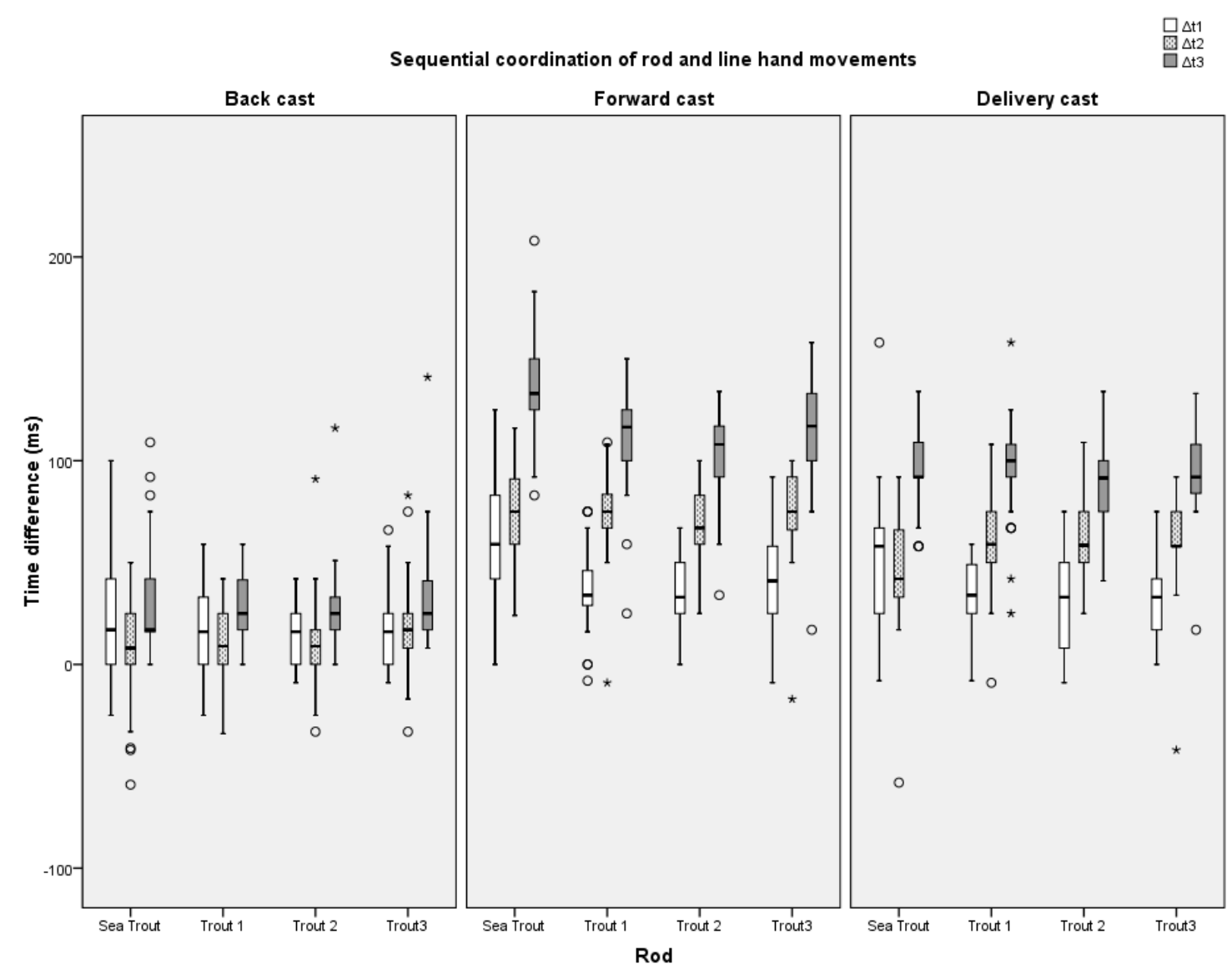

Figure 3. Sequential coordination of the rod and line hand movements. The sequential coordination is presented as the time interval in milliseconds (ms) between the time points of maximum speed of: the translational and the rotational motion of the rod butt $\left(\Delta \mathrm{t}_{1}\right)$, the motion of the line hand relative to the rod butt rotation $\left(\Delta \mathrm{t}_{2}\right)$, and the line hand relative to rod butt translation $\left(\Delta \mathrm{t}_{3}\right)$. Data are presented for the final back and forward false cast and the delivery cast sequences for each cast with the different equipment set-ups: Sea Trout, Trout 1, Trout 2 and Trout 3. Box plots show median and $25^{\text {th }}$ and $75^{\text {th }}$ percentiles, and T-bars representing minimum and maximum values. The points (o) represent outliers that have values deviating more than 1.5 times the box height from the median values, while the asterisks $\left(^{*}\right)$ represent outliers with values deviating more than 3 times the box height.

There was no significant difference in rod and line haul coordination between the different equipment in the back casts: descriptive data are presented in Figure 3.

During the forward false casts, there was a significant difference in $\Delta \mathrm{t}_{1}$ between rods $(F=25.3$, $p<0.01)$, with a significantly larger time difference for Sea Trout compared to Trout 1-3 ( $p<0.01$ for all significant post-hoc comparisons) and for $\Delta \mathrm{t}_{3}$ $(F=29.0, p<0.01)$, with a significantly larger time difference for Sea Trout compared to Trout 1-3 ( $p<0.01$ for all significant post-hoc comparisons). 
During the delivery casts, there were significant differences in $\Delta \mathrm{t}_{1}(F=22.6, p<0.01)$, $\Delta \mathrm{t}_{2}(F=5.9, p=0.01)$ and $\Delta \mathrm{t}_{3}(F=3.1, p=0.028)$ between the different equipment set-ups (Table $3)$. Post-hoc tests showed a significantly larger $\Delta \mathrm{t}_{1}$ for Sea Trout compared to Trout 1-3 ( $p<0.01$ for all significant post-hoc comparisons), and a significantly smaller $\Delta \mathrm{t}_{2}$ for Sea Trout compared to Trout 1-3 ( $p<0.01$ for all significant post-hoc comparisons). Although there was a significant difference between rods for $\Delta \mathrm{t}_{3} \quad(F=3.1$, $p=0.028$ ), a post-hoc test of differences between each of the rods with Bonferroni compensation showed only a tendency toward a smaller time difference for Trout 2 compared to Sea Trout $(p=0.06)$ and for Trout 2 compared to Trout 1
( $p=0.06$ ), and no significance or tendencies for any other comparisons.

Analysis of variance with pooled data from the different equipment set-ups showed significant differences in the peak speed between back cast, forward false cast and delivery cast sequences for $v_{\text {rod }}(F=415, p<0.01), \theta_{\text {rod }}(F=198, p<0.01)$ and $v_{\text {line }}(F=407, p<0.01)$. Post-hoc analyses showed that $v_{\text {rod, }}, \theta_{\text {rod }}$ and $v_{\text {line }}$ were highest during the delivery cast $\left(p<0.01\right.$ for all comparisons). $\theta_{\text {rod }}$ and $v_{\text {line }}$ were lowest during the back cast $(\mathrm{p}<0.01$ for all comparisons), while $v_{\text {rod }}$ was lowest during the forward false cast $(p<0.01$ for all comparisons). Descriptive data for the peak speed during the different cast sequences with the separate equipment are presented in Figure 4.

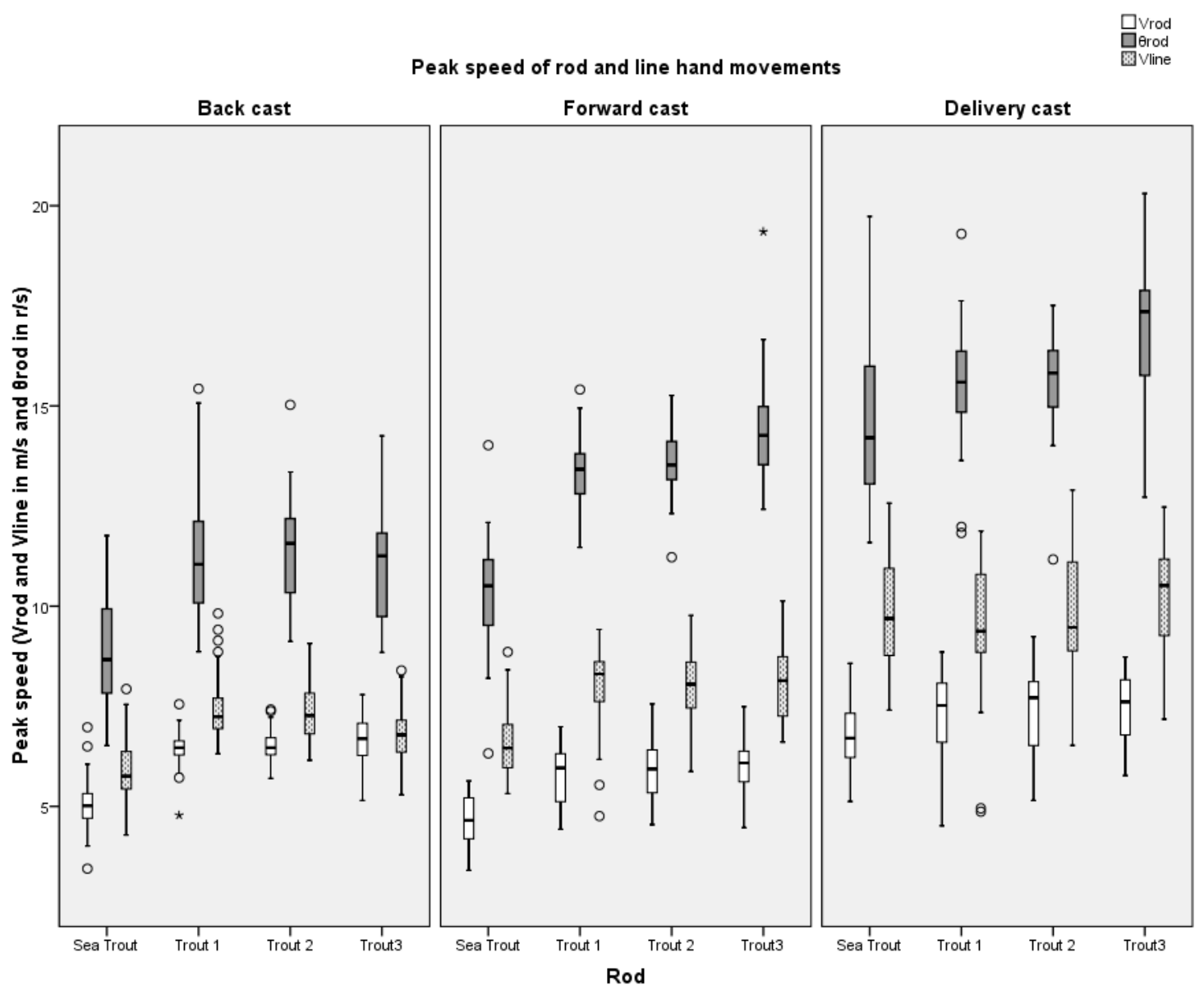

Figure 4. Peak speed of the rod and hand movements. The peak speed of the rod butt translation $\left(v_{\text {rod }}\right)$ and line hand movements $\left(v_{\text {line }}\right)$ are presented as meter per second, while the peak rod butt rotation $\left(\theta_{\text {rod }}\right)$ is presented as radian per second. Data are presented for the final back casts, forward false casts and delivery casts for the different equipment set-ups: Sea Trout, Trout 1, Trout 2 and Trout 3. Box plots show median and $25^{\text {th }}$ and $75^{\text {th }}$ percentiles, and T-bars representing minimum and maximum values. The points (o) represent outliers that have values deviating more than1.5 times the box height from the median values, while the asterisks $(*)$ represent outliers with values deviating more than 3 times the box height. 
During back casts, there were significant differences in $v_{\text {rod }}(F=130, p<0.01), \theta_{\text {rod }}(F=43.5$, $p<0.01)$ and $v_{\text {line }}(F=53.3, p<0.01)$ between equipment set-ups. Post-hoc analyses showed a significantly lower peak speed in rod translation, rod rotation and line haul for Sea Trout compared to Trout $1-3 \quad(p<0.01$ for all comparisons), and a significantly lower peak speed in line haul for Trout 3 compared to Trout 1 and Trout 2 ( $p<0.01$ for both comparisons).

During forward false casts, there were significant differences in $v_{\text {rod }}(F=50.2, p<0.01)$, $\theta_{\text {rod }}(F=163, p<0.01)$ and the $v_{\text {line }}(F=42.0$, $p<0.01)$. Post-hoc analyses showed significantly lower $v_{\text {rod }}, \theta_{\text {rod }}$ and $v_{\text {line }}$ for Sea Trout compared to Trout 1-3 ( $p<0.01$ for all comparisons), while $\theta_{\text {rod }}$ was significantly higher for Trout 3 (i.e., the softest rod), not only compared to Sea Trout, but also compared to Trout 1 and 2 ( $p<0.01$ for both comparisons).

During the delivery cast there were significant differences in $v_{\text {rod }}(F=5.9, p=0.01)$ and $\theta_{\text {rod }}(F=22.6, p<0.01)$, but not in $v_{\text {line }}(F=1.6$, $p=0.19)$ between the different equipment set-ups (Table 3). Post-hoc tests showed significantly lower $v_{\text {rod }}$ and $\theta_{\text {rod }}$ for Sea Trout compared to Trout 1-3 ( $p \leq 0.01$ for all comparisons), while $\theta_{\text {rod }}$ was higher for Trout 3 , (the softest Trout rod) not only compared to Sea Trout but also compared to Trout 1 and $2(p<0.01$ for both comparisons).

\section{DISCUSSION}

The main aim of the study was to describe the coordination of the movements of the fly rod and the line haul during distance casting with onehanded fly rods. The results showed sequential coordination, where the peak translational speed of the rod occurs prior to the peak speed of the angular rotation of the rod; it also showed that the peak speed of the angular rotation of the rod occurs prior to the peak speed of the line haul. This finding was consistent for all cast sequences, i.e., the back and forward false casts and delivery cast, as well as for all four equipment set-ups included in the study, i.e., Sea Trout and Trout 1-3. This "order of events" $\left(\Delta \mathrm{t}_{1}\right.$ $>0, \Delta \mathrm{t}_{2}>0$ and $\left.\Delta \mathrm{t}_{3}=\Delta \mathrm{t}_{1}+\Delta \mathrm{t}_{2}\right)$ has also been observed for shorter false casting with different equipment (Løvoll and Borger, unpublished data), and one could speculate that this will be the case for all efficient hauled casting. In practical terms this suggests that the rotation of the rod and the hauling of the line should be introduced late in each cast sequence compared to the translation of the rod which initiates the cast sequence. There were differences revealed between cast sequences: for example, peak speed was highest during the delivery cast for all measures. A comparison between equipment revealed a significantly lower peak speed of the rod translation and rotation for each cast sequence for Sea Trout (short line) compared to Trout 1-3 (long line).

Our first hypothesis was that the maximum speed of the line haul would occur after the maximum speed of rotation of the rod butt. This was, as mentioned above, confirmed for all cast sequences, i.e., the back and forward false casts as well as the delivery cast. This is probably an adaption in coordination linked to the bending and unbending (straightening) of the rod and thereby giving a time delay between the peak speed of the rotation of the rod butt and the peak speed of the rod tip as described in a previous study (3). The delayed peak speed of line haul compared to rod rotation suggests a synchronizing of peak speed of the line haul with the peak speed of the rod tip, which would seem optimal to maximize the line speed and thereby distance. This study, however, focused on the coordination of the movements of the rod handle (via a sensor on the butt of the rod) and the line hand. How closely the peak speed of the line haul occurs with the peak speed of the rod tip is something that needs to be addressed in a future study with a different measurement system since the sensors of the measurement system used here, i.e., Xsens ${ }^{\circledR}$ motion capture system (Xsens Technologies B.V., Netherlands) were too big and heavy to be attached to the rod tip.

Our second hypothesis was that the coordination of the movements of the rod and the line hand would differ between casting a short line (Sea Trout) compared to long line (Trout 1-3).This was also confirmed by the results. Regarding sequential coordination, it was shown that during forward false casting, there were increased time delays between the peak speed of rod translation and rotation as well 
as between the peak speed of rod translation and line haul for Sea Trout compared to Trout 1-3. During the delivery cast, there was an increased time delay between the peak speed of rod translation and rod rotation, but a decreased time delay between the peak speed of rod rotation and line haul, for Sea Trout compared to Trout 1-3. The latter finding may suggest that there is a shorter time delay between the peak speed of the rod tip compared to the peak speed of the rod butt in Sea Trout compared to Trout 1-3, which seems reasonable due to the fact that stiffer rods are used in Sea Trout. However, as mentioned before, this needs to be investigated with another measurement system whereby the movement of the rod tip can be included in the measurements. Regarding differences in peak speed between short and long lines, it was shown that during false casting (backward and forward), the peak speed of rod translation and rod rotation as well as line haul was lower for Sea Trout compared to Trout 1-3. This may be explained by the longer line in Trout 1-3 needing a higher speed to unroll the loop during each false cast sequence. During the delivery cast, the peak speed of rod translation and rod rotation was lower for Sea Trout compared to Trout 1-3, while no difference was found for the peak speed of the line haul. The differences in the peak speed of rod movements may be explained by the longer and heavier rod, and thereby a larger moment of inertia (MOI), limiting the rod movement speed in Sea Trout compared to Trout 1-3, while the fact that there was no difference in peak speed of the line haul indicates that the maximum line speed via the line haul is what is aimed for during the delivery cast regardless of equipment in distance casting. Moreover, the hauled mass, i.e., the mass of the line which is being hauled, is relatively similar in the delivery cast between Sea Trout and Trout events. This indicates that the line hand inertia, which is likely to be a limiting factor for haul speed, is fairly similar.

Our third hypothesis was that the coordination of the rod and line hand movements would differ due to rod characteristics. More specifically, we hypothesized that the delay in the maximum speed of the line hand would be greater for a softer rod (Trout 3) compared to a stiffer rod (Trout 1 and 2). This hypothesis was not supported by our results since we found no differences between any of the time difference variables between Trout 1-3. Results did, however, reveal a significantly higher peak speed in rod rotation for Trout 3 compared to Trout 1 and 2 both in the forward false cast and the delivery cast. This was likely caused by a smaller chord length for the softer rod (Trout 3) during the cast due to more bending of the rod and thereby also a shorter functional moment distance between the rod tip pulling the line and the axis of rotation. The shorter chord length would thereby lead to a faster angular rotation for the softer rod if using similar muscle force when rotating the different rods. Moreover, we saw a slower peak speed in the line haul for Trout 3 compared to Trout 1 and 2 in the back cast: this finding is, however, more difficult to interpret in any other way than the fact it seems to be an adaptation to the softer rod.

As could be expected, the peak speeds of the rod and line hauling movements were highest during the delivery cast, compared to back and forward false casts. This make sense since the caster aims to maximize line speed, while retaining good control of the movement coordination and acuity of the body and fly rod during the delivery cast to reach maximum casting distance. The fact that the peak speed of the rod rotation as well as line haul were lowest during the back cast seems, however, less optimal. Since only the final back cast sequences, i.e., the back cast preceding the delivery cast, are included in the analyses, it would seem more efficient if the rod and hauling speed, and thereby line speed, was at least as high as the preceding forward false cast. This difference may be compensated for partly by the higher peak speed of rod translation in the back cast compared to the forward false cast. It is likely that there are biomechanical constraints, including limitations of joint range of motion and muscle force production, that limit the possibility to increase the peak speed of the rod rotation and line haul during the back cast compared to the forward cast. This is partly supported by the fact that several muscles that are involved in the rotation of the rod in the back cast, including the external rotator and flexor muscles of the shoulder and the extensor muscles of the wrist, 
have less strength compared to their antagonists, i.e., the shoulder medial rotator and extensor muscles and the wrist flexor muscles, which are mainly involved in the forward cast $(19,20)$. However, maximum force measures were not assessed for the back and forward cast movements; this is, therefore, merely speculative and needs further investigation.

This is the first assessment of the coordination of the rod and hand movements during the double haul in fly casting. The use of IMU sensors has previously been shown to have an acceptable accuracy compared to golden standard optical motion tracking systems (18), and the results from this study provide important information about movement behavior in distance fly casting. Future research should, however, also include assessments of the motion of the rod tip and the fly line, which demands another type of measurement system, e.g., an optical motion tracking system with small lightweight reflector markers and/or reflective paint spray. Such a study would provide further insight into the timing of the line haul and rod tip movements and its effects on line speed and casting distance.

Limitations of this initial pilot study include the small group of participants, and the fact that the study is limited to highly experienced fly fishers who also practice and compete in Fly Casting. This makes the results difficult to generalize to other fly fishers and fly casters. However, since the studied casters were highly skilled, we have reason to believe that the observed coordination of movement is an optimized adaptation for distance fly casting. Different fly fishers and fly casters use different casting styles, e.g., some casters use a more vertical rod alignment while others use a more horizontal rod alignment during the back and forward cast sequences. In the group of casters in this study, two casters used a relatively vertical casting style, while two used a more horizontal style. Since the measurements are consistent within this group with various casting styles, this suggests that the results may be generalizable to elite casters in fly casting and unrelated to casting style. Future larger studies with elite as well as intermediate fly casters will shed further light on this topic.

\section{CONCLUSION}

The results support the fact that, among elite casters, single-handed fly casting with double haul is coordinated in an order of events whereby the peak speed occurs first for the translation of the rod, then for the rotation of the rod and finally for the line haul. This finding was consistent for all cast sequences and for all equipment set-ups included in the study. There are differences in movement coordination between casting sequences and tackle set-ups, which relates to the line length and rod stiffness. The results of this study have implications for the instruction and practice of fly fishing and fly casting, and are especially important for longdistance fly casting using the double haul technique.

\section{APPLICABLE REMARKS}

- The findings of maximum speed occurring first in rod translation, thereafter in rod rotation and finally in line hauling movement can be considered movement adaptations to optimize line speed and thereby distance and efficiency in fly casting.

- These results support the principle that the rotation of the rod and the hauling of the line should occur relatively late in each cast sequence, i.e., after an initial translation of the rod in the movement direction.

- The results also indicate that the coordination of rod and hauling movements should be adapted to line length, where increased rod and line hauling speed is used for longer lines.

- In general, this suggests that casting movements need to be changeable and adjusted to current circumstances to optimize rod and line movements. 


\section{ACKNOWLEDGEMENTS}

The authors would like to thank the Swedish Casting Association for their help completing the study and financial help with travel costs for the fly casters participating in the study. Thanks to
Stefan Siikavaara, Magnus Hedman and Joakim Karlsson who together with the first author performed the casts that the analyses are based on. A special thanks also to Ibro Ribic, Olof Ekfeldt and Mats Olsson for help with data collections.

\section{REFERENCES}

1. Arlinghaus R, Cooke SJ. Recreational fisheries: socioeconomic importance, conservation issues and management challenges. In: Dickson B, Hutton J, Adams WM, editors. Recreational hunting, conservation and rural livelihoods: science and practice. Oxford: Blackwell Publishing; 2009. p. 39-58.

2. Röijezon U, Siikavaara S. A comparison of distance fly casting performance between three 5-weight long-belly floating lines. Open Sports Sci J. 2012;5:118-22.

3. Løvoll G, Borger J. The rod \& the cast2007 [cited $2010 \quad 10$ March. Available from: http://www.flycastinginstitute.com/e-libraryfiles/FCI_E-L_Rod_Cast_102507.pdf.

4. Matsuo T, Escamilla RF, Fleisig GS, Barrentine SW, Andrews JR. Comparison of kinematic and temporal parameters between different pitch velocity groups. J Appl Biomech. 2001;17(1):1-13.

5. Hirashima M, Kadota H, Sakurai S, Kudo K, Ohtsuki T. Sequential muscle activity and its functional role in the upper extremity and trunk during overarm throwing. J Sports Sci. 2002;20(4):301-10.

6. Hirashima M, Yamane K, Nakamura Y, Ohtsuki T. Kinetic chain of overarm throwing in terms of joint rotations revealed by induced acceleration analysis. J Biomech. 2008;41(13):2874-83.

7. Fleisig GS, Escamilla RF, Andrews JR, Matsuo T, Satterwhite Y, Barrentine SW. Kinematic and kinetic comparison between baseball pitching and football passing. J Appl Biomech. 1996;12(2):207-24.

8. Liu H, Leigh S, Yu B. Sequences of upper and lower extremity motions in javelin throwing. J Sports Sci. 2010;28(13):1459-67.

9. Bartlett R, Muller E, Lindinger S, Brunner F, Morriss C. Three-dimensional evaluation of the kinematic release parameters for javelin throwers of different skill levels. J Appl Biomech. 1996;12(1):58-71.

10. Wagner H, Pfusterschmied J, Tilp M, Landlinger J, von Duvillard SP, Muller E. Upper- body kinematics in teamhandball throw, tennis serve, and volleyball spike. Scand J Med Sci Sports. 2014;24(2):345-54.

11. Elliott B, Marsh T, Blanksby B. A 3-dimensional cinematographic analysis of the tennis serve Int J Sport Biomech. 1986;2(4):260-71.

12. Marshall RN, Elliott BC. Long-axis rotation: The missing link in proximal-to-distal segmental sequencing. $\mathrm{J}$ Sports Sci. 2000;18(4):247-54.

13. Allen JR, O'Keefe KB, McCue TJ, Borger JJ, Hahn ME. Upper extremity kinematic trends of fly-casting: Establishing the effects of line length. Sports Biomech. 2008;7(1):38-53.

14. Hoffmann JA, Hooper MR. Fly rod response. J Sound Vib. 1998;209(3):537-41.

15. Wang G, Wereley N. Analysis of fly fishing rod casting dynamics. Shock Vib. 2011;18(6):839-55.

16. Gatti-Bono C, Perkins NC. Numerical model for the dynamics of a coupled fly line/fly rod system and experimental validation. J Sound Vib. 2004;272(3-5):773-91.

17. Zhou H, Stone T, Hu H, Harris N. Use of multiple wearable inertial sensors in upper limb motion tracking. Med Eng Phys. 2008;30(1):123-33.

18. Lebel K, Boissy P, Hamel M, Duval C. Inertial measures of motion for clinical biomechanics: comparative assessment of accuracy under controlled conditions-effect of velocity. PLoS One. 2013;8(11):e79945.

19. Marley RJ, Thomson MR. Isokinetic strength characteristics in wrist flexion and extension. Int J Ind Ergon. 2000;25(6):633-43.

20. Ivey FM, Calhoun JH, Rusche K, Bierschenk J. Isokinetic testing of shoulder strenght: normal values Arch Phys Med Rehabil. 1985;66(6):384-6. 